\title{
Recent advances and novelties in the thin cell layer-based plant biotechnology - a mini-review
}

\author{
Jaime A. TeixeIra DA Silva*, JUdit DobránSZKI \\ University of Debrecen, Debrecen, Hungary
}

\begin{abstract}
Plant thin cell layers (TCLs), which consist of a few layers of cells, are typically $0.5-1 \mathrm{~mm}$ thick. After the first application of TCLs to tobacco in 1943, and after 45 years of their practical application to plant tissue culture, TCLs have proven to be an effective tool for the in vitro culture of dozens of plant species. Their higher productivity compared to conventional explants has made TCLs continually relevant and useful in plant research and applied plant biotechnology. On the 45th anniversary of TCLs, this mini-review highlights the emergence of about a dozen new studies published in the past three years (2016-2018) that employed TCLs in either basic tissue culture or applied in vitro biotechnology. These new results emerged for medicinal plants (Bacopa monnieri, Scutellaria ocmulgee, Urginea altissima, Withania coagulans), fruit trees (Rubus spp.), vegetables (Allium ascalonicum, Allium schoenoprasum), a conifer (Pinus patula), ornamental plants including Lilium and three orchids (Dendrobium aqueum, Dendrobium aphyllum, Malaxis wallichii), and a model plant (Arabidopsis thaliana). In plant biotechnology, TCLs have a rich history and their continued use and future application to plant tissue culture or genetic transformation is promising.
\end{abstract}

Key words: fruit and vegetables, in vitro culture, medicinal and ornamental plants, micropropagation, model plant, TCL, tissue culture

TCLs in in vitro organogenesis: history, successes, limitations, and applications

In a conventional plant tissue culture, small (cells and tissues) or large (a full organ) plant fragments may be used as explants for in vitro regeneration or organogenesis. Three examples include $5 \mathrm{~mm}$ sections from leaves in apple (Malus $\times$ domestica Borkh.), $5 \mathrm{~mm}$ wide proto-

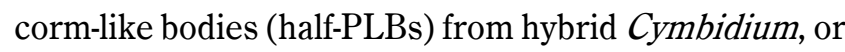
$8 \mathrm{~mm}$ internode sections from chrysanthemum (Dendranthema grandiflora Kitamura) (Teixeira da Silva and Dobránszki, 2014). Unlike conventional explants, the TCL technology requires the use of thin or ultrathin sections, typically $0.1-2 \mathrm{~mm}$ in thickness (Nhut et al. 2003; Teixeira da Silva and Dobránszki, 2014). Preparation of these explants requires stability of hand and thus intensive labor is necessary that does not currently allow the technique to be mechanized, thereby restricting its use across a wide range of plant species (Teixeira da Silva and Tanaka, 2011). Despite this, TCLs have served as useful alternative explants for dozens of plant species, now exceeding 100 (Teixeira da Silva and Dobránszki, 2015). The TCL portfolio includes plant species for which well-established regeneration protocols exist such as the model plants tobacco (Nicotiana tabacum L.) and Arabidopsis thaliana (L.) Heynh. (Teixeira da Silva and Dobránszki, 2013a) and a number of ornamental plants (Teixeira da Silva et al., 2007). TCLs as transverse sections (tTCLs) were seminally applied to tobacco and Nautilocalyx lynchii (Hook. f.) Sprague 45 years ago (Tran Thanh Van, 1973a, 1973b). However, a search on Scopus and PubMed indicates that TCLs have not been used as a practical form of micropropagation or in vitro regeneration for tobacco for at least a decade, suggesting that this technique might not necessarily be practically useful, at least not for tobacco.

The selection of an explant can determine the outcome of organogenesis in vitro and is an important parameter that a tissue culture researcher must optimize

\footnotetext{
*Corresponding author: jaimetex@yahoo.com
} 
when conducting trials prior to initiating any tissue culture experiment (Teixeira da Silva et al., 2015a; Bhattacharyya et al., 2018; Ramírez-Mosqueda et al., 2018). This is because in the presence of the same plant growth regulators (PGRs) that are supplemented in in vitro regeneration media, different explants may display different responses. Thus, TCLs offer researchers a greater precision because, in the case of longitudinal TCLs (ITCLs), the explant consists of only one or two tissue types, such as the epidermis and sub-epidermis, whereas tTCLs may have various tissues (Nhut et al., 2003b). Therein lies the practical importance of TCLs. Experiments conducted with apple (Malus $\times$ domestica), an orchid (Cymbidium), and an ornamental plant (chrysanthemum) showed that when considering productivity (number of shoots or desired regenerating organs) per unit area of an explant, TCLs produced many more regenerants than conventional explants (Teixeira da Silva and Dobránszki, 2014). For example, in apple "Freedom", five shoots formed per leaf (conventional explant), but once a growth correction factor was applied that took into account the area, size, shape, and volume of TCLs relative to regular explants, leaf tTCLs produced 65 shoots per leaf (for "Gala" apple, the values were 24 and 286, respectively). This potential nature of TCLs to produce, in theory, many more propagules than conventional explants (a single explant can be divided, once sliced, into multiple TCLs) might ensure that the technique will continue to be used in the future and explored for new plant species. The use of TCLs in rhizogenesis studies in $A$. thaliana to understand the mechanism of adventitious rooting has allowed this system to be employed for fundamental research in plant developmental biology (Teixeira da Silva et al., 2015a; Della Rovere et al., 2016; Fattorini et al., 2017). The importance of TCLs in the plant tissue culture and in vitro biotechnology, now and in the future, is thus optimistic.

Orchids are important ornamental plant species; many of them are rare, while some have medicinal properties. These orchids include members of the Dendrobiumgenus, which are widely used in traditional Chinese medicine (Teixeira da Silva and Ng, 2017). Thus, the ability to have a tissue culture system that can produce a larger number of clonal propagules, relative to conventional explants, makes TCLs attractive to researchers and the ornamental industry. To date, the TCL technology has been used in tissue culture or micropropagation of 19 orchid species spanning 13 genera where it has also been used for the induction of cultures leading to in vitro flowering (Teixeira da Silva, 2013; Teixeira da Silva et al., 2014; Teixeira da Silva and Dobránszki, 2015) or the induction of somatic embryos, which are equivalent to PLBs (Teixeira da Silva and Winarto, 2016). When used with juvenile tissues of conifer and forestry tree species that are usually difficult to micropropagate since mature tissues tend to be recalcitrant in vitro (Benson, 2000; Bonga, 2017), TCLs offer a viable opportunity for regeneration. As one recent example, Pinus patula Schiede ex Schltdl. \& Cham is of great economic importance due to its use for reforestation. However, no efficient mass propagation system is available for this species due to its recalcitrance to in vitro morphogenesis and development. Despite these limitations, Ramírez-Mosqueda et al. (2018) developed an efficient in vitro protocol to induce embryogenic callus from TCL segments originated from immature zygotic embryos. Conventional protocols can therefore be used to establish tissue cultures from in vitro material, or in vitro regenerants can serve as the source of in vitro-derived TCLs (Malabadi and Teixeira da Silva, 2011; Bonga, 2017).

The following sections describe how TCLs have been used to advance recent research in medicinal plants, horticultural species (vegetables, fruit trees), conifers, and ornamental plants.

\section{TCLs: advances for medicinal plants}

Tissue culture and micropropagation of medicinal plants form the basis for their industrial use and biotransformation, commercialization of their active compounds, or preservation of genetic resources (Máthé et al., 2015). Recently, four studies using TCLs on medicinal plants were conducted, namely Bacopa monnieri (L.) Pennell (Croom et al., 2016), Scutellaria ocmulgee Small (Vaidya et al. 2016), Urginea altissima (L.f.) Baker (Baskaran et al., 2018), and Withania coagulans (Stocks) Dunal (Tripathi et al., 2018).

Using Murashige and Skoog (1962) (MS) or B5 (Gamborg et al., 1968) basal media, Vaidya et al. (2016) used $S$. ocmulgee leaf and petiole tTCLs (the length and width were 1225.50 and $107.65 \mu \mathrm{m}$, respectively) derived from in vitro plants to assess shoot regeneration in the presence of several PGRs. Although control explants (no PGRs) produced no shoots, the maximum shoot production was from leaf-derived tTCLs (102 shoots per 
tTCL) in the presence of $5 \mu \mathrm{M}$ 6-benzyladenine (BA), $1 \mu \mathrm{M}$ 1-naphthaleneacetic acid (NAA), and $1 \mu \mathrm{M}$ maltose on B5 medium. In most PGR treatments, leaf-derived tTCLs produced more shoots per tTCL than petiole-derived tTCLs, independently of the basal medium. tTCL-derived shoots (developed under a $16-\mathrm{h}$ photoperiod) rooted in the presence of $5 \mu \mathrm{M}$ indole-3-butyric acid (IBA) and eventually acclimatized. Moreover, tTCLs served as explants for genetic transformation using the Agrobacterium tumefaciens strain EHA105 carrying two reporter genes, $\beta$-glucuronidase $(G U S)$ and green fluorescent protein $(G F P)$. Stable $G U S$ staining and $G F P$ fluorescence were observed in genetic transformants, and the presence of transgenes was verified by using molecular methods (PCR, RT-PCR, and Southern blot analysis).

Using a very similar strategy as that used by Vaidya et al. (2016) and the same culture conditions, Croom et al. (2016) used leaf and internode (stem) tTCLs to induce shoots in $B$. monnieri, the optimal medium being MS with $10 \mu \mathrm{M}$ BA, forming 59 and 33 shoot buds per tTCL, respectively. For the genetic transformation protocol, the same plasmid and protocol as for $S$. ocmulgee were used. As a result, Croom et al. obtained stable genetic transformants expressing GUS and GFP.

Uperoleia altissima leaf 1TCLs formed 17.4 shoots per explant after incubation for 4 weeks in a liquid MS basal medium supplemented with $2 \mu \mathrm{M} \mathrm{BA}$ and $10 \mu \mathrm{M}$ meta topolin followed by transfer to a semi-liquid medium for 8 more weeks under a 16 -h photoperiod (Baskaran et al., 2018). In such a case, $100 \%$ of ITCLs formed shoots, whereas explants in the PGR-free control formed none. Rooting of ITCL-derived shoots was effective on a number of auxin-supplemented media, but the most effective combination was $5 \mu \mathrm{M}$ IBA and $2.5 \mu \mathrm{M}$ NAA, resulting in the formation of 9.8 roots/shoot. All in vitro plantlets acclimatized well in a substrate of vermiculite and soil $(1: 1, \mathrm{v} / \mathrm{v})$.

In a study by Tripathi et al. (2018), 5.63 shoots per stem tTCL were formed in a solid MS basal medium with $0.5 \mu \mathrm{M}$ BA and $2.5 \mu \mathrm{M}$ NAA under a 16 -hr photoperiod. The shoots were rooted in $9.8 \mu \mathrm{M}$ IBA, and $90 \%$ of plantlets were acclimatized in a substrate of soil and sand $(1: 1, \mathrm{v} / \mathrm{v})$.

\section{TCLs: advances for horticultural species (vegetables, fruit trees) and a conifer}

In some vegetable or fruit species, when trying to use conventional explants, the application of biotechno- logical methods (in vitro propagation, genetic engineering, etc.) might not be applicable due the lack of a reliable tissue culture method for plantlet regeneration. The application of TCLs can breach recalcitrance, or slow in vitro growth, allowing an in vitro culture and whole-plant regeneration for several plant species (reviewed in Teixeira da Silva and Dobránszki, 2013a, 2015; Ramírez-Mosqueda, 2018). In this sub-group of plant species, TCLs were used in the regeneration of fruit trees (Rubus spp.) (Sabooni and Shekafandeh, 2017); two vegetables, shallot (Allium ascalonicum L.) (Hidayat, 2016) and chive (Allium schoenoprasum L.) (Tubić et al., 2018); and a conifer, Pinus patula Schiede ex Schltdl. \& Cham. (Ramírez-Mosqueda et al., 2018).

In a study by Sabooni and Shekafandeh (2017), an organogenic callus was induced from the stem tTCLs derived from in vitro Rubus sanctus "High Prickle" and Rubus hirtus Roxb. "Low Prickle" plantlets in MS medium supplemented with $2.32 \mu \mathrm{M}$ kinetin (KIN), $2.69 \mu \mathrm{M}$ NAA, and $8.88 \mu \mathrm{M} \mathrm{BA}$, while the embryogenic callus was induced for both cultivars on a half-strength MS medium with $9.76 \mu \mathrm{M} \mathrm{KIN}$ and $7.99 \mu \mathrm{M}$ BA. The transfer of an embryogenic callus to MS medium with $7.57 \mu \mathrm{M}$ abscisic acid and a malt extract or glutamine stimulated the formation of somatic embryos that were then germinated on a halfstrength MS medium supplemented with $4.88 \mu \mathrm{M}$ BA, $2.02 \mu \mathrm{M}$ gibberellic acid, and $0.05 \mu \mathrm{M}$ NAA. Plantlets were transferred to a PGR-free MS medium and acclimatized in a substrate of autoclaved peat and perlite $(1: 1$, $\mathrm{v} / \mathrm{v})$, although the success of acclimatization was not quantified. The use of sucrose at $6 \%(\mathrm{w} / \mathrm{v})$ induced the embryogenic callus in as much as $80 \%$ of tTCLs but in only $20 \%$ when $3 \%$ sucrose was used. The role of the sucrose during somatic embryogenesis can be dual. It can act as a stressor-causing or an osmotic agent (Gaj, 2004 ), or it may serve as a signal for reorienting the developmental program into the direction of a somatic embryo development (León and Sheen, 2003).

In a study by Hidayat (2016), the shoot tip tTCLs of A. ascalonicum "Sumenep" were used to induce shoots (16-h photoperiod) in the Dunstan and Short (1977) basal medium supplemented with $0.25 \mu \mathrm{M}$ BA and $2.5 \mu \mathrm{M}$ NAA, resulting in the formation of 8.6 shoots per tTCL. By contrast, 2.16 and 4.65 shoots per explant were formed from conventional shoot tips after 9 and 15 weeks of culture, respectively. Using a 3-1 bioreactor, Hidayat was able to induce 240 plantlets from 15 tTCLs within 10 
weeks of culture. This result fortifies the notion that the outcome or variation in in vitro productivity may depend on the timing of sampling (Teixeira da Silva and Dobránszki, 2013b). Earlier studies related to the productivity of apple leaf tTCLs, and the effect of sampling time, had already been proven (Teixeira da Silva and Dobránszki, 2013b, 2014). However, we also reported that the effect of timing of sampling depended on the genotype, position of the source explant, and the choice of PGRs used in the regeneration medium. In an easy-to-regenerate cultivar (Royal Gala), extending the regeneration period from 7 to 9 weeks increased the number of regenerated shoots per explant both in conventional and tTCL explants. However, in a difficult-to-regenerate cultivar (Freedom), the timing of sampling did not affect the shoot number per tTCL in the optimal PGR content, whereas the shoot number per conventionalexplant was significantly higher after 9 weeks (Dobránszki and Teixeira da Silva, 2013).

Tubic et al. (2018) used TCLs in the in vitro culture of $A$. schoenoprasum. tTCLs were derived from the bases of leaf sheaths of in vitro plantlets, and cultured in MS medium supplemented with $10 \mu \mathrm{M}$ thidiazuron (TDZ) that resulted in shoot formation from $100 \%$ of explants, forming an average of 20 shoot buds per tTCL. The formation of shoots, but significantly lower than after TDZ was used, was also possible when KIN, BA, or metatopolin was used. Without the need to transfer the shoots to media with an auxin, the authors found that roots were formed effectively from shoots in the presence of several cytokinins, although equally high rooting rate was observed in the PGR-free MS medium.

Ramírez-Mosqueda et al. (2018), who fortified the established foundation of research related to somatic embryogenesis in the Pinus genus (Teixeira da Silva and Malabadi, 2012), prepared ITCLs and tTCLs from immature $P$. patula zygotic embryos and compared the efficiency of somatic embryogenesis with conventional explants, complete immature zygotic embryos. The medium used was a WPM medium (McCown and Lloyd, 1981) supplemented with $4.44 \mu \mathrm{M}$ BA and $4.5 \mu \mathrm{M} 2,4-$ dichlorophenoxyacetic acid, resulting in $88.7 \%$ and $90 \%$ of tTCLs and ITCLs, respectively, forming an embryogenic callus, although no somatic embryos were produced. It is likely that the lack of differences in callus formation between both TCL types was because the authors used two versions of tTCLs, erroneously referring to a longitudinally prepared tTCL as an ITCL.

\section{TCLs: advances for ornamental plants and orchids}

The mass propagation of different ornamental plants has frequently been achieved by a tissue culture based on the use of the TCL technique. Lilium longiflorum Thunb. has served as a model plant for the TCL technique, and TCLs have been used successfully to mass propagate at least two dozen orchid species or hybrids, or for the in vitro propagation of other ornamental plants from more than 15 genera, including Saintpaulia, Begonia, Pelargonium, Gentiana, Gladiolus, Iris, Petunia, and Rosa (reviewed in studies by Teixeira da Silva, 2013; Teixeira da Silva and Dobránszki, 2013a, 2015). TCL-basedresearch hasadvanced recently for ornamental plants like including Lilium (Marinangeli, 2016) and three orchids, Dendrobium aqueum Lindl. (Parthibhan et al., 2018), Dendrobium aphyllum (Roxb.) C.E.C. Fisch. (Bhattacharyya et al., 2018), and Malaxis wallichii (Lindl.) Deb (Bose et al., 2017).

Tissue culture and biotechnology of Dendrobium, an important medicinal orchid and ornamental plant (Teixeira da Silva and Ng, 2017), are evolving rapidly with many advances being made annually (Teixeira da Silva et al., 2015b). Novel techniques that offer assistance and solutions to orchid researchers who may encounter difficulties or limitations in tissue culture are always welcomed. Advancing both basic tissue culture and conservation biology, Parthibhan et al. (2018) induced somatic embryos from $41 \%$ of stem tTCLs of $D$. aqueum in MS medium supplemented with $2.3 \mu \mathrm{M}$ zeatin or in $10 \%$ of explants in the presence of $8.3 \mu \mathrm{M} N^{6}$-(2-isopentenyl) adenine. In the latter case, as many as 43 globular somatic embryos per tTCL were formed. In a study by Bhattacharyya et al. (2018), shoot development was induced on 0.1-0.4 mm thick nodal tTCLs of $D$. aphyllum using $15 \mu \mathrm{M}$ metatopolin, $10 \mu \mathrm{M} \mathrm{TDZ}$, and $10 \mu \mathrm{M} \mathrm{AgNO}_{3}$ in the medium. tTCL technology was superior to earlier methods (Talukdar, 2001; Dutta et al., 2011; Hossain et al., 2013), forming 39.4 shoots per explant after 8 weeks of culture. Shoots were rooted with a high frequency (82.34\%) when $15 \mu \mathrm{M}$ IBA was used and the plantlets were successfully acclimatized in a mixture of vermiculite : saw dust $(1: 1, \mathrm{v} / \mathrm{v})$.

In a study by Bose et al. (2017), adventitious shoots were induced from stem tTCLs in $89 \%$ of explants, forming 22.5 shoots per tTCL when plated in MS basal medium with $4.1 \mu \mathrm{M}$ metatopolin and $2.7 \mu \mathrm{M}$ NAA. Shoots 
were then rooted in a half-strength MS medium with $5.7 \mu \mathrm{M}$ indole-3-acetic acid. After acclimatizing plants in vermiculite, the authors noted a higher antioxidant activity in acclimatized plantlets than that in in vitro shoots.

Marinangeli (2016) described a detailed protocol for the application of tTCLs from the microbulbs of Lilium hybrids ("White Heaven", Asiatic Hybrid "Nello", longiflorum $\times$ Asiatic Hybrid "Royal Respect", and longiflorum $\times$ Oriental Hybrid "Triumphator") to induce bulbs, the embryogenic callus, and shoots. The protocol involved five developmental stages and media, with media 1-4 using MS basal medium while medium 5 used halfstrength MS. The five media, and the respective organogenic outcome, were as follows: 1) bulb induction: $1.5 \mu \mathrm{M}$ NAA; 2 ) bulb enlargement: $0.54 \mu \mathrm{M}$ NAA and $0.46 \mu \mathrm{M}$ Kin; 3) embryogenic callus induction: $5.5 \mu \mathrm{M}$ NAA and $0.45 \mu \mathrm{M} \mathrm{TDZ;} \mathrm{4)} \mathrm{embryogenic} \mathrm{callus} \mathrm{prolifera-}$ tion: $5.5 \mu \mathrm{M}$ NAA and $0.23 \mu \mathrm{M}$ TDZ; 5) regeneration (microshoot formation): PGR-free. All five media contained $3 \%$ sucrose, except for medium 2 , which contained $9 \%$ sucrose. No visual evidence was provided to support these claims of regeneration, nor was any histological or cytological proof of somatic embryogenesis provided.

\section{Possible reasons for the success of TCL technology}

Over the past few decades, methods based on TCLs as explants were developed and successfully applied to numerous plant species for in vitro mass propagation, genetic transformation, production of artificial seed, cryopreservation, and in vitro selection (Kozgar and Kahn, 2012; Sharma et al., 2013; Teixeira da Silva, 2013; Teixeira da Silva and Dobránszki, 2013a, 2015). For plant biotechnology, the use of TCL technology might be highly beneficial in many ways, as listed below, contributing to its success.

1. When TCL explants are used, the surface area of the explant in contact with the medium is relatively greater than in a conventional explant, and the transport of medium components is more efficient because they can reach relatively more receptive cells of the explants, i.e. which would enable an organogenic or embryogenic response, relative to conventional explants (Tran Than Van, 2003). As a result of these properties, when used as explants TCLs can be more receptive to environmental, chemical, or physical stimuli. TCLs may thus be beneficial when used in cause-and-effect style studies.
2. The sensitivity of TCLs to different inputs from the in vitro environment is high. For example, light at the beginning of culture blocked shoot regeneration from leaf tTCLs of apple 'Freedom' completely (Dobránszki and Teixeira da Silva, 2011). Due to their higher sensitivity to environmental factors, TCLs have been successfully applied for in vitro selection (Kozgar and Kahn, 2012).

3. The stress response caused by wounding can induce callus formation and differentiation. In TCLs, the wounded surface of the explant is relatively higher than in a conventional explant (Tran Than Van, 2003). This may be one reason why TCLs may be a simple but practical solution for breaking recalcitrance to in vitro growth and morphogenesis, as was observed in P. patula (Ramírez-Mosqueda et al., 2018) and D. aphyllum (Bhattacharyya et al., 2018). However, there is no guaranty that the increased callus production will increase organogenesis or somatic embryogenesis. Some organs, if used as conventional explants, may display a low morphogenic or organogenic potential, but can be involved in regeneration or even in mass propagation if TCLs are prepared from them, as was demonstrated in apple in vitro stem segments (tTCLs) for shoot regeneration (Teixeira da Silva and Dobránszki, 2015).

4. In genetic transformation, it is advantageous to employ explants that have only a single tissue layer such as ITCLs or a few layers such as the epidermis, especially where regeneration occurs from epidermal or sub-epidermal tissues (Nhut et al. 2003a). The use of TCL-based regeneration systems would allow a greater surface area to be infected, although this can pose challenges in removing the Agrobacterium or avoiding excessive bacterial growth and explant contamination (Teixeira da Silva and Fukai, 2001; Gnasekaran et al., 2014). However, Agrobacterium overgrowth can be successfully suppressed during transformation by using the Agrobacterium strain harboring the $S a c B-S a c R$ gene cassette (Liu et al., 2016). In this construction, the $S a c B$-SacR gene cassette is used as a negative selection marker, which is able to hinder the overgrowth of Agrobacterium. Inserting $S a c B$-SacR at the recAlocus of $A$. tumefaciens strain GV2260 made the Agrobacterium sensitive to the quantity of sucrose in the medium, i.e., its growth was inhibited when the sucrose content in the me- 
dium was increased. By contrast, the use of TCLs would effectively match the use of particle bombardment to introduce plasmids or other DNA constructs of interest, since the DNA-coated microprojectiles would enter the few layers of tissues in a TCL. This would ensure that a greater proportion of tissue in a subsequent regeneration is genetically transformed. These issues have previously been discussed in the context of orchid genetic transformation and biotechnology (Teixeira da Silva, 2013).

5. If studies are conducted on morphoanatomical changes and morphogenesis, the use of TCLs is more beneficial because preparation of samples for light or electron microscopy is much easier from TCL explants than from thicker conventional explants, which would facilitate histological observations and confirmation of the origin of an organ (Della Rovere et al., 2015; Teixeira da Silva et al. 2015).

6. If the availability of plant material is limited during in vitro culture establishment or subcultures, it is beneficial to use TCLs as explants for increasing the number of explants and, thereby, the efficiency of the subculture and culture establishment.

7. TCLs might actually be more productive than a conventional explant, especially when assessing the number of regenerating organs per source organ, even if the actual productivity per TCL is less than that from the conventional explant. This was demonstrated in three plant species (Cymbidium hybrid, chrysanthemum, and apple) when two new concepts, the plant growth correction factor and the geometric factor (Teixeira da Silva and Dobránszki, 2014), were applied. Across species, when these two factors were applied, the relative productivity of TCL explants was between 10-fold and 13-fold higher than that of conventional explants.

\section{Conclusions}

TCLs will continue to be used in basic and applied plant biotechnology, but mainly in regeneration studies. In the new plant species explored in this mini-review from 2016-2018, it was found that after media and culture conditions had been optimized, higher organogenesis or somatic embryogenesis resulted from the use of TCLs. In at least two cases, tTCLs served as the donor explants for genetic transformation experiments (Croom et al., 2016; Vaidya et al., 2016), and root-derived TCLs continue to serve as basic tools in assessing axillary root development in $A$. thaliana (Della Rovere et al., 2016; Fattorini et al., 2017, 2018). Except for three studies (Bose et al., 2017; Bhattacharyya et al., 2018; Parthibhan et al., 2018), none of the other new studies, similar to the vast majority of older studies on TCLs (Teixeira da Silva and Dobránszki, 2015), assessed the genetic stability relative to plants derived from the conventional culture, and such genetic testing needs to be implemented in future research on TCLs. Parthibhan et al. (2018) used inter-simple sequence repeats (ISSR) to confirm the monomorphic nature of the resulting somatic embryos. Bose et al. (2017) tested genetic fidelity by flow cytometry and intron splice junction (ISJ) markers, finding some polyploidy (5-11\% 8C) in the leaves of the donor and acclimatized plants when the former was used, and 5-17\% polymorphism in tissue cultured plants when five of the 15 ISJ primers were used. Bhattacharyya et al. (2018), on the other hand, applied interretrotransposon-targeted amplified region (IRAP) and ISSR separately and in combination to evaluate the genetic fidelity of regenerated shoots. The detected polymorphism depended on the methods applied: it was $7.69 \%, 4.00 \%$, and $5.26 \%$ when IRAP, ISSR, and IRAP + ISSR were used, respectively. TCLs could be useful for the study of chimeras owing to their capability to isolate specific layers or tissues that can phenotypically be identified as chimeras, such as leaf color chimeras.

\section{Author contribution statement}

Both the authors have contributed to the planning, development, and editing of this review.

\section{Conflicts of interest}

The authors declare no conflict of interest.

\section{Acknowledgment}

The research was financed by the Higher Education Institutional Excellence Program of the Ministry of Human Capacities in Hungary, within the framework of the Biotechnology thematic program of the University of Debrecen (20428-3/ 2018/FEKUTSTRAT).

\section{References}

Baskaran P., Kumari A., Van Staden J. (2018) In vitro propagation via organogenesis and synthetic seeds of Urginea altissima (L.f.) Baker: a threatened medicinal plant. 3 Biotech 8: 18 .

Benson E.E. (2000) In vitro plant recalcitrance: an introduction. In Vitro Cell. Dev. Biol. Plant 36: 141-148. 
Bhattacharyya P., Prasenjit P., Kumaria S., Tandon P. (2018) Transverse thin cell layer ( $t$-TCL)-mediated improvised micropropagation protocol for endangered medicinal orchid Dendrobium aphyllum Roxb: an integrated phytomolecular approach. Acta Physiol. Plant. 40: 137.

Bonga J.M. (2017) Can explant choice help resolve recalcitrance problems in in vitro propagation, a problem still acute especially for adult conifers? Trees 31: 781-789.

Bose B., Kumaria S., Choudhury H., Tandon P. (2017) Insights into nuclear DNA content, hydrogen peroxide and antioxidative enzyme activities during transverse thin cell layer organogenesis and ex vitro acclimatization of Malaxis wallichii, a threatened medicinal orchid. Physiol. Mol. Biol. Plants 23: 955-968.

Croom L.A., Jackson C.L., Vaidya B.N., Parajuli P., Joshee N. (2016) Thin cell layer (TCL) culture system for herbal biomass production and genetic transformation of Bacopa monnieri L. Wettst. Amer. J. Plant Sci. 7: 1232-1245.

Della Rovere F., Fattorini L., D'Angeli S., Veloccia A., Del Duca S., Cai G., Falasca G., Altamura M.M. (2015) Arabidopsis SHR and SCT transcription factors and AUX1 auxin influx carrier control the switch between adventitious rooting and xylogenesis in planta and in in vitro cultured thin cell layers. Ann. Bot. 115: 617-628.

Della Rovere F., Fattorini L., Ronzan M., Falasca G., Altamura M.M. (2016) The quiescent center and the stem cell niche in the adventitious roots of Arabidopsis thaliana. Plant Signal. Behavior 11: e1176660.

Dobránszki J., Teixeira da Silva J.A. (2013) In vitro shoot regeneration from transverse thin cell layers of apple leaves in response to various factors. J. Hortic. Sci. Biotechnol. 88: 60-66.

Dunstan D.I., Short K.C. (1977) Improved growth of tissue cultures of onion, Allium cepa. Physiol. Plant. 41: 70-72.

Dutta S., Chowdhury A., Bhattacharjee B., Natha P.K., Dutta B.K. (2011) In vitro multiplication and protocorm development of Dendrobium aphyllum (Roxb.) CEC Fisher. Assam Univ. J. Sci. Technol. 7: 57-62.

Fattorini L., Veloccia A., Della Rovere F., D’Angeli S., Falasca G., Altamura M.M. (2017) Indole-3-butyric acid promotes adventitious rooting in Arabidopsis thaliana thin cell layers by conversion into indole-3-acetic acid and stimulation of anthranilate synthase activity. BMC Plant Biol. 17: 121.

Fattorini L., Hause B., Gutierrez L., Veloccia A., Della Rovere F., Piacentini D., Falasca G., Altamura M.M. (2018) Jasmonate promotes auxin-induced adventitious rooting in dark-grown Arabidopsis thaliana seedlings and stem thin cell layers by a cross-talk with ethylene signalling and a modulation of xylogenesis. BMC Plant Biology 18: 182.

Gaj M.D. (2004) Factors influencing somatic embryogenesis induction and plant regeneration with particular reference to Arabidopsis thaliana (L.) Heynh. Plant Growth Reg. 43: 27-47.

Gamborg O.L., Miller R.A., Ojima K. (1968) Nutrient requirements of suspension cultures of soybean root cells. Exp. Cell Res. 50: 151-158.
Gnasekaran P., Jeyanthi J., Antony J., Uddain J., Subramaniam S. (2014) Agrobacterium-mediated transformation of the recalcitrant Vanda Kasem's Delight orchid with higher efficiency. Scientific World J. Article ID 583934: 10 pp.

Hidayat I.M. (2016) The use of thin cell layer (TCL) explants in micropropagation of shallot (Allium ascalonicum L.). Acta Hortic. 1143: 251-258.

Hossain M.M., Sharma M., Pathak P. (2013) In vitro propagation of Dendrobium aphyllum (Orchidaceae) - seed germination to flowering. J. Plant Biochem. Biotechnol. 22: 157-167.

Kozgar M.I., Khan S. (eds) (2012) Induced mutagenesis in crop plants. Biorem. Biodiv. Bioavail. 6(special issue 1): $118 \mathrm{pp}$.

León P., Sheen J. (2003) Sugar and hormone connections. Trends Plant Sci. 8: 110-116.

Liu Y., Miao J., Traore S., Kong D., Liu Y., Zhang X., Nimchuk Z.L., Liu Z., Zhao B. (2016) SacB-SacR gene cassette as the negative selection marker to suppress Agrobacterium overgrowth in Agrobacterium-mediated plant transformation. Front. Mol. Biosci. 3: 70.

Malabadi R.B., Teixeira da Silva J.A. (2011) Thin cell layers: application to forestry biotechnology. In: Rao M.N.V., Soneji J. (Eds) Focus on Tree Micropropagation. Tree Forestry Sci. Biotechnol. 5(Special Issue 1): 14-18.

Marinangeli P. (2016) Somatic embryogenesis of Lilium from microbulb transverse thin cell layers. [in:] In vitro embryogenesis in higher plants. Methods in molecular biology, vol. 1359. Eds. Germanà M., Lambardi M. Humana Press, New York, NY, pp. 387-394.

Máthé Á., Hassan F., Abdul Kader A. (2015) In vitro micropropagation of medicinal and aromatic plants. [in:] Medicinal and aromatic plants of the world. Ed. Máthé Á. Springer, Dordrecht.

McCown B., Lloyd G. (1981) Woody plant medium (WPM) a mineral nutrient formulation for microculture of woody plant species. HortScience 16: 453.

Murashige T., Skoog F. (1962) A revised medium for rapid growth and bioassays with tobacco tissue cultures. Physiol. Plant. 15: 473-497.

Nhut D.T., Murthy H.N., Teixeira da Silva J.A. (2003a) Usefulness of thin cell layers in plant transformation. Prop. Ornamental Plants 2(2): 30-38.

Nhut D.T., Teixeira da Silva J.A., Aswath C.R. (2003b) The importance of the explant on regeneration in thin cell layer technology. In Vitro Cell. Dev. Biol. - Plant 39: 266-276.

Nhut D.T., Tran Thanh Van K., Le B.V., Thorpe T. (Eds.). (2003) Thin Cell Layer Culture System: Regeneration and Transformation Applications, Kluwer Academic Publishers, Dordrecht, The Netherlands.

Parthibhan S., Rao M.V., Teixeira da Silva J.A., Senthil Kumar T. (2018) Somatic embryogenesis from stem thin cell layers of Dendrobium aqueum. Biol. Plant. 62: 439-450.

Ramírez-Mosqueda M.A., Iglesias-Andreu L.G., Armas-Silva A.A., Cruz-Gutiérrez E.J., de la Torre-Sánchez J.F., LeyvaOvalle O.R., Galán-Páez C.M. (2018). Effect of the thin cell 
layer technique in the induction of somatic embryos in Pinus patula Schl. et Cham. J. For. Res. (in press) Doi: 10.1007/s11676-018-0663-0

Sabooni N., Shekafandeh A. (2017) Somatic embryogenesis and plant regeneration of blackberry using the thin cell layer technique. Plant Cell Tiss. Organ Cult. 130:313-321.

Sharma S., Shahzad A., Teixeira da Silva J.A. (2013) Synseed technology-a complete synthesis. Biotechnol. Adv. 31: 186-207.

Talukdar A. (2001) Multiple shoot induction in Dendrobium aphyllum Roxb. J. Orchid Soc. India 15: 35-38.

Teixeira da Silva J.A. (2013) The role of thin cell layers in regeneration and transformation in orchids. Plant Cell Tiss. Organ Cult. 113: 149-161.

Teixeira da Silva J.A., Altamura M.M., Dobránszki J. (2015a) The untapped potential of plant thin cell layers. J. Hortic. Res. 23: 127-131.

Teixeira da Silva J.A., Cardoso J.C., Dobránszki J., Zeng S-J. (2015b) Dendrobium micropropagation: a review. Plant Cell Rep. 34: 671-704.

Teixeira da Silva J.A., Dobránszki J. (2013a) Plant thin cell layers: a 40-year celebration. J. Plant Growth Reg. 32: 922-943.

Teixeira da Silva J.A., Dobránszki J. (2013b) How timing of sampling can affect the outcome of the quantitative assessment of plant organogenesis. Sci. Hortic. 159: 59-66.

Teixeira da Silva J.A., Dobránszki J. (2014) Dissecting the concept of the thin cell layer: theoretical basis and practical application of the plant growth correction factor to apple, Cymbidium and chrysanthemum. J. Plant Growth Reg. 33: 881-895.

Teixeira da Silva J.A., Dobránszki J. (2015) Plant thin cell layers: update and perspectives. Folia Hortic. 27: 183-190.

Teixeira da Silva J.A., Fukai S. (2001) The impact of carbenicillin, cefotaxime and vancomycin on chrysanthemum and tobacco TCL morphogenesis and Agrobacterium growth. J. Appl. Hortic. 35: 71-77.

Teixeira da Silva J.A., Kerbauy G.B., Zeng S-J., Chen Z-L., Duan J. (2014) In vitro flowering of orchids. Crit. Rev. Biotechnol. 34: 56-76.

Teixeira da Silva J.A., Malabadi R.B. (2012) Factors affecting somatic embryogenesis in conifers. J. For. Res. 23: 503-515.
Teixeira da Silva J.A., Ng T-B. (2017) The medicinal and pharmaceutical importance of Dendrobium species. Appl. Microbiol. Biotechnol. 101: 2227-2239.

Teixeira da Silva J.A., Tanaka M. (2011) Thin cell layers: The technique. In: Davey M., Anthony P. (Eds.). Plant Cell Culture: Methods Express, Wiley-Blackwell, Chichester, UK, pp. 25-37.

Teixeira da Silva J.A., Tran Thanh Van K., Biondi S., Nhut D.T., Altamura M.M. (2007) Thin cell layers: developmental building blocks in ornamental biotechnology. Floriculture Ornam. Biotechnol. 1: 1-13.

Teixeira da Silva J.A., Winarto B. (2016) Somatic embryogenesis in two orchid genera (Cymbidium, Dendrobium). In: In Vitro Plant Embryogenesis in Higher Plants, Eds. Germanà M.A., Lambardi M. Springer Science+Business Media-Humana Press, Berlin, Germany, pp. 371-386.

Tran Thanh Van M. (1973a) In vitro control of de novo flower, bud, root and callus differentiation from excised epidermal tissues. Nature 246: 44-45.

Tran Thanh Van M. (1973b) Direct flower neoformation from superficial tissue of small explants of Nicotiana tabacum $L$. Planta 115: 87-92.

Tran Thanh Van M. (2003) Thin cell layer concept. In: Nhut D.T., Van Le B., Tran Thanh Van K., Thorpe T. (eds) Thin Cell Layer Culture System: Regeneration and Transformation Applications. Kluwer Academic Publisher, Dordrecht, The Netherlands.

Tripathi D., Rai K.K., Rai S.K., Rai S.P. (2018) An improved thin cell layer culture system for efficient clonal propagation and in vitro withanolide production in a medicinal plant Withania coagulans Dunal. Ind. Crops Products 119: 172-182.

Tubić L., Savić J., Mitić N., Milojević J., Janošević D., Budimir S., Zdravković-Korać S. (2016) Cytokinins differentially affect regeneration, plant growth and antioxidative enzymes activity in chive (Allium schoenoprasum L.). Plant Cell Tiss. Organ Cult. 124: 1-14.

Vaidya B.N., Jackson C.L., Perry Z.D., Dhekney S.A., Joshee N. (2016) Agrobacterium-mediated transformation of thin cell layer explants of Scutellaria ocmulgee small: a rare plant with anti-tumor properties. Plant Cell Tiss. Organ Cult. 127: 57-69. 